Dorota Klimecka-Tatar ${ }^{1}$

\title{
APPLICATIONS OF DIGITAL ANALYZER TO CHARACTERIZING THE STRUCTURES OF Ni-Cr-Mo DENTAL CASTING ALLOYS
}

\begin{abstract}
This paper presents the possibility of carrying out a structural quantitative analysis of the alloys commonly used in dentistry. On the basis of microscopic observation and digital treatments (LUT and binarization) it was possible to determine the contribution of the phase structure of the Ni-Cr-Mo alloy. The results revealed that differences in the chemical and structural composition of Remanium dental alloys, easily identifiable on the basis of digital image analysis.
\end{abstract}

Key words: digital analysis, $\mathrm{Ni}-\mathrm{Cr}-\mathrm{Mo}$ alloy, $\mathrm{Ni}$ alloy

\section{Introduction}

Modern computer software, provides wide possibilities for modification of the image which are virtually useless for quantitative metallography analysis. These modifications can improves difficult to verify images, but also highlight details that may become a key argument in the final decision concerning the selection and use of engineering materials. Full use of the analyzer in the form of computer programs (commercial and free), allows to make necessary quantitative evaluation of metallographic studies with a high degree of accuracy. Replacing manual measurement techniques by digital method, introduced a number of changes in the processes of research, so that it became possible to eliminate laborious and inaccurate calculations. Advanced computer programs, facilitating the analysis of geometric features revealed by the metallographic structures. Based on mathematical models, created sets of algorithms that, when properly programmed, perform the following consecutive sequences of operations. In this way

${ }^{1}$ Dr inż., Czestochowa University of Technology, Faculty of Management, Institute of Production Engineering, e-mail: klimt@ wip.pcz.pl 
computational efficiency is increased significantly.

This paper presents the method of digital analysis of the structure morphology of the Ni-Cr-Mo dental casting alloys and present differences in morphology based on the quantitative contribution of different phases. Such measurements provide a range of information on the possibilities and alloys designing (morphology and structure designing), which is extremely important when deciding on the selection of material use in the oral cavity of the patient. However, the results accurately reflect the facts of the imaged area is necessary to verify the converted image (digitized) with the original image.

\section{Digital image analysis in metallography}

Image analysis is a very important field of material metallography examination. In the present, the concept of the image, there is a set of elements, which consist of a lot of radically differing objects. The main features affecting on their diversity is a technology of registration and image processing method. In materials science image analysis research focuses on the structures observed by: optical microscopes, electron microscopes, registration uses x-ray probe, mass spectroscopes, ultrasonic spectroscopes, etc.

Analysis of the information that is somehow hidden in the image is carried out in various ways. There are two main directions: qualitative analysis and quantitative analysis.

Research carried out under the account of qualitative analysis, used primarily to recognize objects on analyzed image, based on representing only a small part of material structure (WOJNAR L., KURZYDŁOWSKI K.J., SZALA J. 2002).

The purpose of quantitative analysis, first of all is getting data from the objects in the image, and present them in numerical form. Analyzing the image, there is a need to repeatedly count of objects, the number of which is very large. These objects usually have an irregular shape, which results in very large obstacles in their aggregation. The problem 
also enhances the size of various types of objects, which digitally discernible difference between the largest and the smallest, can oscillate on a scale of 1: 16.000.000. In this analysis we are able to obtain data defining: the number of objects, their size, shape and location (WOJNAR L., KURZYDŁOWSKI K.J., SZALA J. 2002)

For a quantitative description of metallographic structure, in addition to the determination of numerical parameters, consists a number of preparatory procedures. They depend on a determining the appropriate measurement conditions, and proper preparation of downloads research materials. The stages of digital operations, should visualized the information to make possible to distinguish between appropriate structural systems, their shape, size, and object location. The appearance faithfully reproduce metallographic surface, is one of the most important operations needed for quantitative analysis (WOJNAR L., KURZYDŁOWSKI K.J., SZALA J. 2002, SZALA J. 2003)

\subsection{Image analysis technique}

A very important role before the start of the analysis is to ensure the high quality of registered image (high sharpness and contrast). If the image has only grayscale, or black and white, format takes the form of 8 bit. This is the number of possible shades for each one point (pixels). This number of gray levels is 255 , whereas in the case of color images, this number increased to over 16 million. This is due to the occurrence of red, green and blue color called. RGB format. Each individual color has 8 bits, after the summation gives 24 bits corresponding to each pixel. The first steps of images processing is transforming bearing name of "look-up tables" shortly LUT (Fig. 9.1.b, Fig. 9.2). After their implementation changed the display mode of the image. The images were subjected to a series of changes aimed to improve and enhance the morphology of the structure (WOJNAR L., KURZYDŁOWSKI K.J., SZALA J. 2002, SZALA J. 2003). 


\subsection{Binarization}

The aim of binary transformation is to eliminate all colors and shades, except for two base: white and black. This transformation is one of the most important and is necessary for proper image analysis, as only in this format the digital measurements can be used. Binarization can determine the change into zero-one system. This is an approach where a digital "0" is assigned to black, and "1" to white (Fig. 9.1c, Fig. 9.3). Filtration was carried out using the signals corresponding to the strengthening of the edge disclosure. It is one of the most important and also most difficult modification. There are a number of filters that can be used to specify the edges, among others: Prewitt filter, Robertsa filter (WOJNAR L., KURZYDŁOWSKI K.J., SZALA J. 2002, SZALA J. 2003).

\subsection{Digital measurements}

The objects counting is carried out by means of histogram digital analysis, which for each image, created individual record in the form of quantitative diagram. It allows you to specify the number of shades of all pixels, which the tonal range in the case of 32-bit images is very heterogeneous. However, these measurements are consistent and correct, necessary was appropriate image processing, and its transformation into binary form. However, these measurements are consistent and correct, if necessary image processing is leaded (transformation into binary form).

Measurement of binary histogram was the most important element of quantitative research. Its diagram presented data on the alignment of tones, which as the sum of object, divided by the surface area of the entire image, according to the formula (Table 9.1):

$$
\bar{a}=\frac{V_{V}}{N_{A}}
$$

where:

$\bar{a}-$ averaged surface area,

$V_{V}$ - volume of the object subjected to analysis, 
$N_{A}$ - multiplicity of object.

\section{The characteristic of Ni-Cr-Mo alloys structure}

Despite excellent properties of Ni-Cr-Mo alloys, about their suitability for use as biomaterial is not only biotolerant but also structure morphology. On the basis of experimental data (TURCHIAI P.E.A., KAUFMANB L., LIUC ZI-KUI 2006) it has been identified thermodynamic equilibrium phase system of Ni-Cr-Mo alloys composition similar to commercial alloy (named Remanium alloy) (WWW.DENTERUM.DE, RADOMSKA K., KLIMECKA-TATAR D. 2013, ORLICKI R., KŁAPTOCZ B. 2003, RADOMSKa K., KLIMECKA-TATAR D., JAGIELSKA-WiADEREK K. 2013, TURCHIAI P.E.A., KAUFMANB L., LIUC ZI-KUI 2006). Accordingly in the material structure above the $1250^{\circ} \mathrm{C}$ temperature, only one stable phase, $\gamma$ regular phase (face-center cubic - FCC) is present. It is estimated that around $850^{\circ} \mathrm{C}$, the structure of an alloy containing $\sim 60 \% \mathrm{Ni}$, can be still single-phase but depending on the presence of alloying elements in the structure another phase can be formed. During alloy cooling from $1250^{\circ} \mathrm{C}$ temperature small inclusions in the form of carbides can be formed. It is also observed the formation of phases based on complex crystalline structures such as phase $\sigma, \mu$, or P, having a significant impact on the overall mechanics of alloys and their corrosion resistance (PERRICONE M.J., DUPONT J.N. 2006).

Research confirms that in equilibrium state, at low temperatures, in all tested varieties $\mathrm{Ni}-\mathrm{Cr}-\mathrm{Mo}$, should disclose the multiphase structure contains regular face-centered cubic structure $\gamma$ (Ni rich), and one or two complex-type phase $\sigma, \mu$, or P. Together with Ni-Cr-Mo alloy cooling $\gamma$-rich $\mathrm{Ni}$ phase is partly replaced by phases enriched in $\mathrm{Mo}$ and $\mathrm{Cr}$ (TURChiai P.E.A., KAUFMANB L., LiUC ZI-KUi 2006, KLIMECKA-TATAR D., JAGIELSKA-WIADEREK K. 2013, ORLICKI R., KŁAPTOCZ B. 2003). 

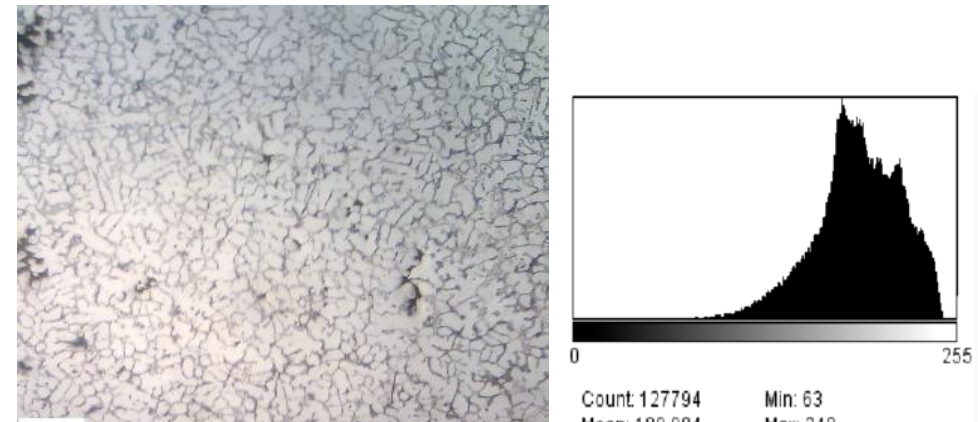

a
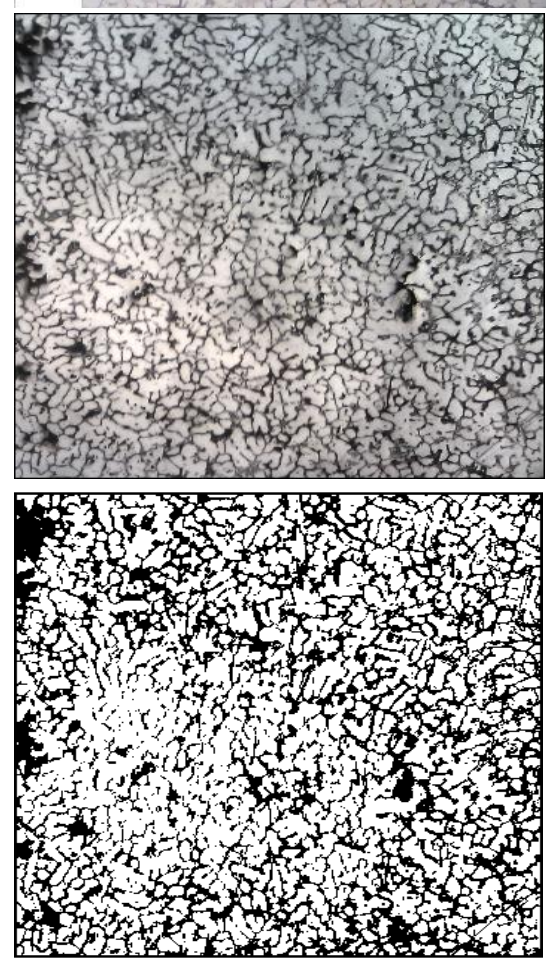

Count: 127794 Mean 189.904 StdDev: 28.836

Max 248

Mode: $179(2102)$
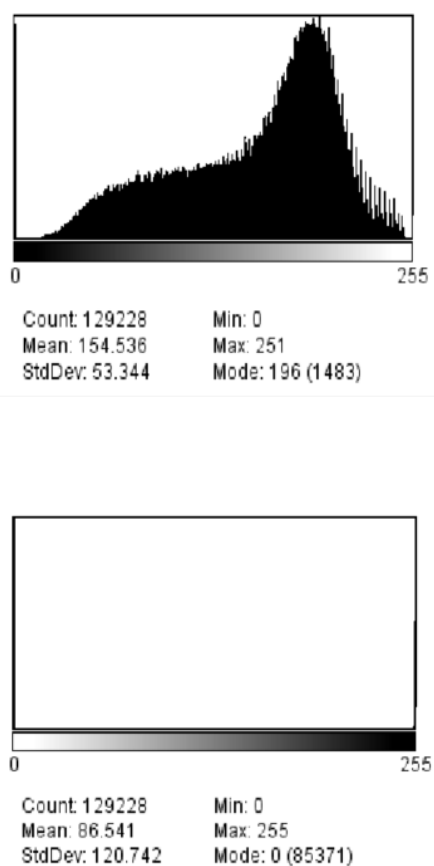

Fig. 1. The microstructure of the Remanium G (Ni-Cr-Mo) alloy: a) original image, b) after transformation $L U C, c)$ after binarization.

Source: own study 
Zeszyty Naukowe

No. $1(1)$

Quality. Production. Improvement

2014

pp. $88-98$

a)

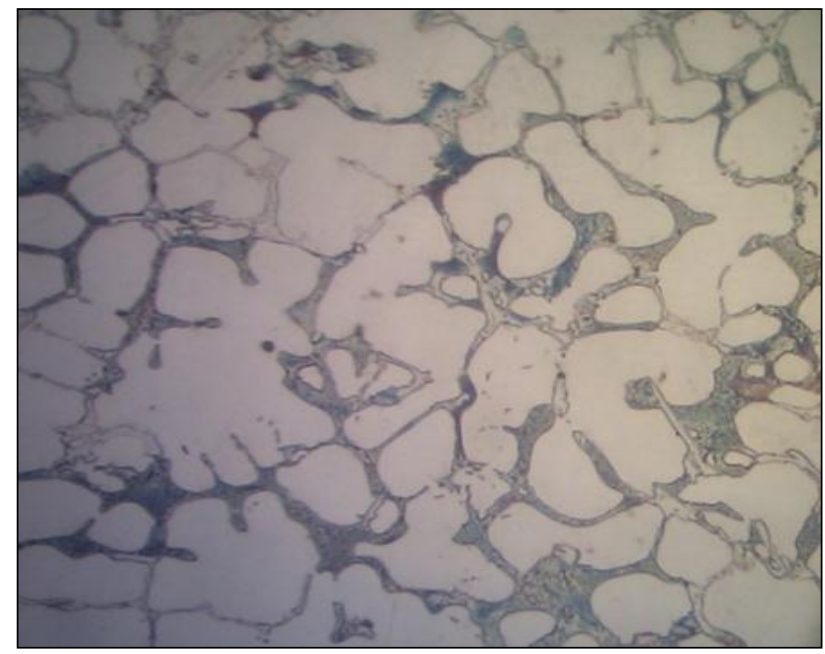

b)

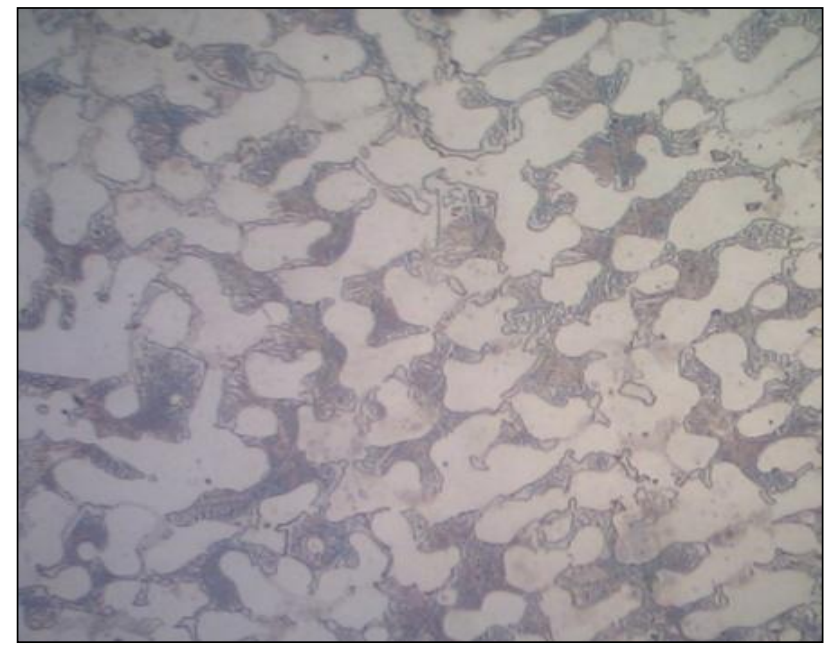

Fig. 2. Mictrostructure images of Ni-Cr-Mo alloys: a) Remanium G-soft 400x, b) Remanium CSe 400x - original images. Source: own study 
Zeszyty Naukowe

No. $1(1)$

Quality. Production. Improvement

2014

pp. $88-98$

a)

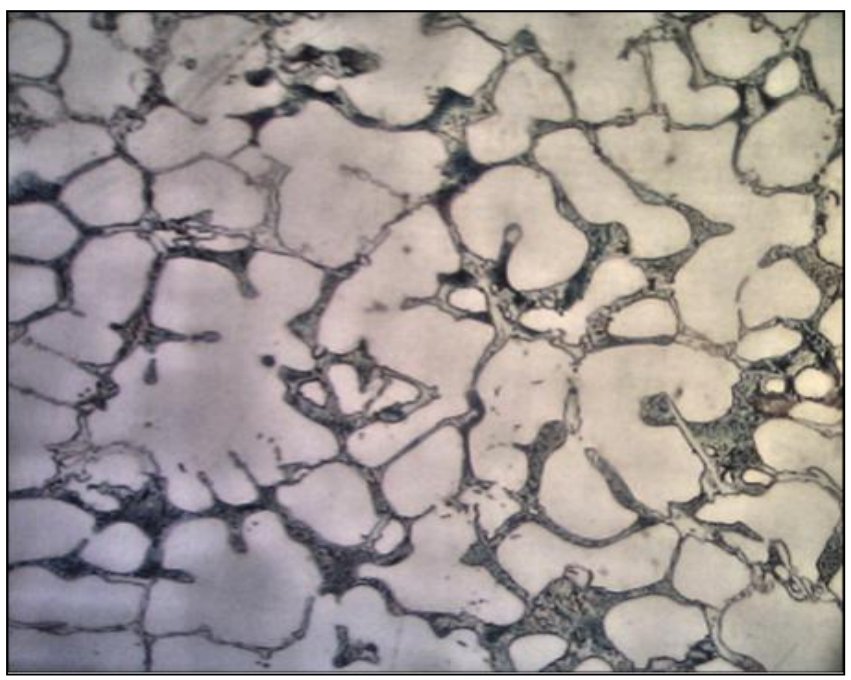

b)

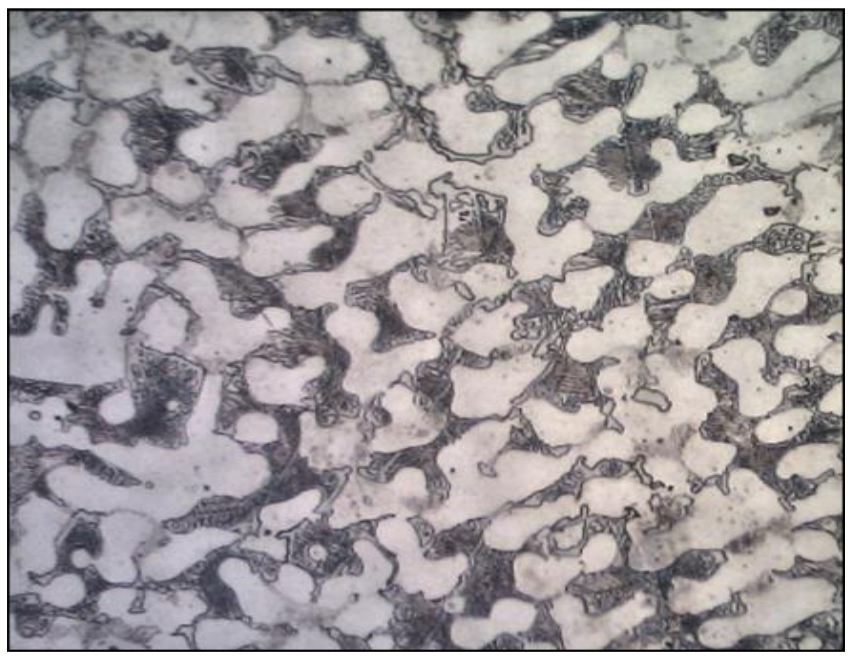

Fig. 3. Mictrostructure images of Ni-Cr-Mo alloys: a) Remanium G-soft 400x, b) Remanium CSe 400x - after LUT transformation

Source: own study 
a)

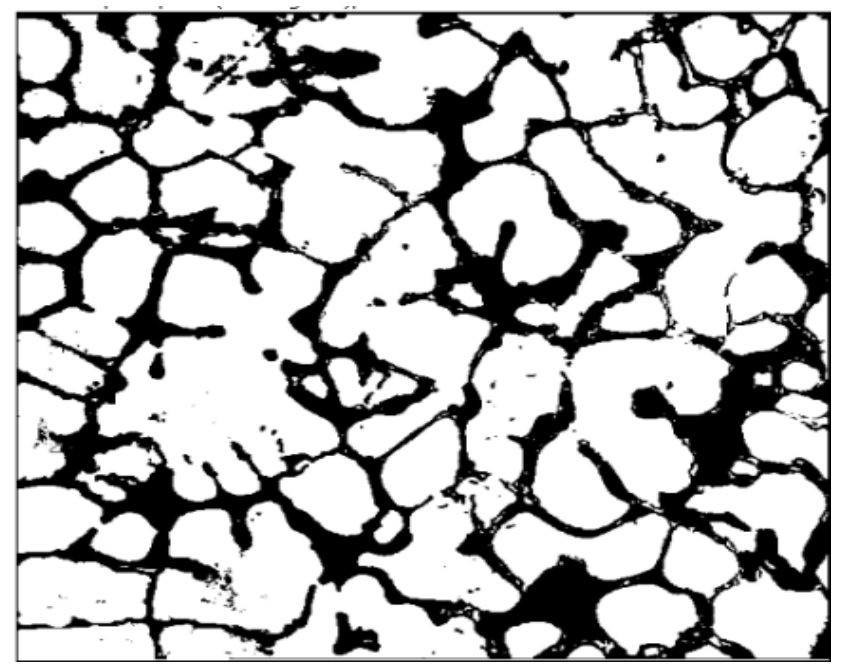

b)

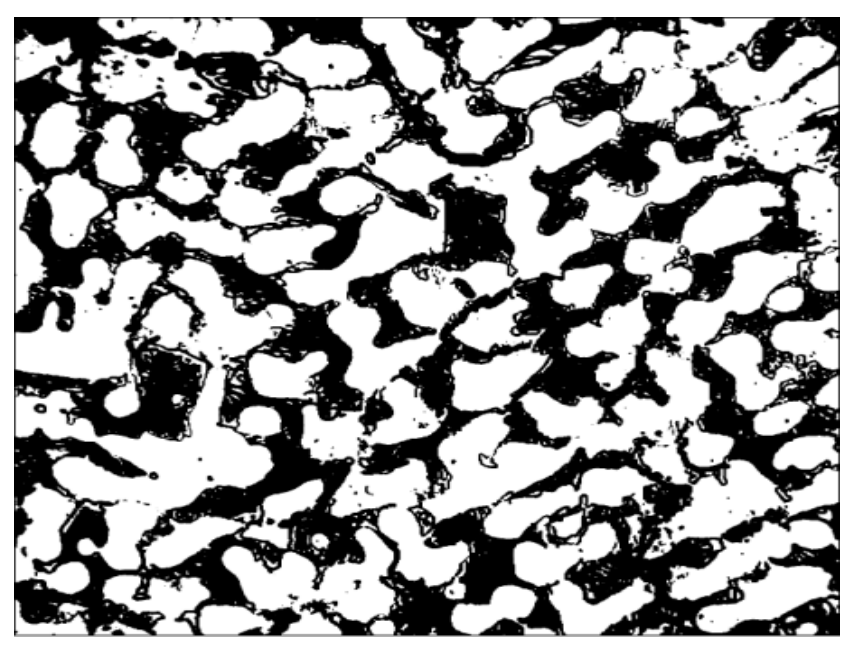

Fig. 4. Mictrostructure images of Ni-Cr-Mo alloys: a) Remanium G-soft 400x, b) Remanium CSe 400x - after binarization 
Results obtained in the quantitative analysis on the Remanium G-soft and CSe alloys, in Table 1 were presented.

Table 9.1. The tonal distribution, the percentage of precipitates 255

\begin{tabular}{|c|c|c|c|}
\hline & White (0) & Black (255) & $\begin{array}{c}\text { Black } \\
\text { percentage, } \%\end{array}$ \\
\hline $\begin{array}{c}\text { Remanium } \\
\text { G-soft (400x) }\end{array}$ & 1070576 & 445024 & 29,36 \\
\hline $\begin{array}{c}\text { Remanium } \\
\text { G-soft (100x) }\end{array}$ & 926387 & 589213 & 38,88 \\
\hline $\begin{array}{c}\text { Remanium } \\
\text { CSe (400x) }\end{array}$ & 933112 & 582488 & 38,43 \\
\hline $\begin{array}{c}\text { Remanium } \\
\text { CSe (100x) }\end{array}$ & 871920 & 643680 & 42,47 \\
\hline
\end{tabular}

Source: own study

The studied images of has been subjected to a number of transformations, so that it was possible to scan every digital point into account the value assigned to one of the 255 shades of gray. To obtain correct results, the binarization process was conducted and all shades were standardized and then assigned to values of 0 or 255 , respectively corresponding to white and black. Evidence of the correct binarization process is the lack of recognition of the program, any tone ranges from 1 to 254 Therefore, the results from the interval between the value ton 18 to 237 have been omitted.

\section{Summary}

Demonstrated data, describe the important feature, which is the quantitative analysis (percentage value of $\gamma$ phase, Ni-rich) of Ni-Cr-Mo alloys structures. An averaged participation of the Ni-rich phase in the structure in the alloy Remanium G-Soft is approx. 66\%, while in Remanium CSe less than $60 \%$. Based on the collected literature data, and 
the analysis of equilibrium diagrams for Ni-Cr-Mo alloys noted that the alloys with the smaller amount of additives elements (such as: $\mathrm{Mo}, \mathrm{Si}, \mathrm{C}$, Be etc.) (WWW.DENTERUM.DE) characterized with the higher volume of $\gamma$ phase. Differences in content of these elements confirmed that the Remanium CSe alloy has more extensive interdendritic spaces and reduced participation of Ni-rich phase more than Remanium G-soft alloy. Such structural features are more suitable for metallic materials for veneering with ceramic material. Thus, the digital analysis easily can assist in the selection of dental materials and helps in eliminating and mistakes avoiding.

\section{Bibliography}

1. Data from the manufacturer www.denterum.de

2. ORLICKI R., KŁAPTOCZ B. 2003. Inżynieria Stomatologiczna Biomaterialy. Tom I nr 1, s. 3.

3. Perricone M.J., Dupont J.N. 2006. Effect of Composition on the Solidification Behavior of Several Ni-Cr-Mo and Fe-Ni-Cr-Mo Alloys. Met. And Trans. Vol. 37A, s. 1267-1280.

4. RADOMSKA K., KLIMECKA-TATAR D. 2013. The effect of melting/casting method of $\mathrm{Ni}-\mathrm{Cr}-\mathrm{Mo}$ dental alloy on the corrosion resistance in ringer solution, Ochrona przed Korozją 11, s. 527-530.

5. Radomska K., Klimecka-Tatar D., Jagielska-WiadereK K. 2013. Dental alloy corrosion characteristics remanium $\mathrm{G}$ ( $\mathrm{Ni-Cr}-\mathrm{Mo}$ ) melting/casting by different techniques, Ochrona przed Korozją 57, s. 262268.

6. SZALA J. 2003. Komputerowa analiza obrazu w metalografii ilościowej, Informatyka w technologii Materiałów Nr 1. Tom 3.

7. Turchiai P.E.A., KaufManB L., LiUC ZI-KUi 2006. Modeling of $\mathrm{Ni}-\mathrm{Cr}-\mathrm{Mo}$ based alloys: Part I- phase stability. Computer Coupling of Phase Diagram and Thermochemistry 30. p.7-87.

8. Wojnar L., KurzydŁowski K.J., SZALa J. 2002. Praktyka Analizy Obrazu. PTS. Kraków. 